\title{
A Learning Community: Teaching Technical Writing in the Chemical Engineering Unit Operations Laboratory
}

\author{
Stephanie D. Loveland, Chemical and Biological Engineering,
} prairie@iastate.edu

Sheryl D. McGough, English, smcgough@iastate.edu

Iowa State University, Ames IA 50011

\section{Abstract}

A new approach to teaching technical writing skills to chemical engineering undergraduate students has been implemented by the authors. These students are required to take two laboratory courses, and in these courses they are required to complete reports in several different formats, including both written reports and oral presentations. In addition, the students are required to take a technical writing course offered by the English department. By linking the first laboratory course with the technical writing course in a learning community, the students have realized many benefits. First, there is consistent instruction provided on how to write technical reports, which are tailored to the chemical engineering profession. Second, a peer mentor is provided. This person has already completed both of the classes associated with the learning community and provides additional help and instruction outside of class times. Third, there are some "linked" assignments: (1) a single report is submitted in both courses at the same time and is evaluated by both the lab staff and the English instructor. This allows for feedback from multiple readers and allows students to better understand how to write for a broad audience; (2) a final design project proposal is assigned and evaluated jointly by both of the instructors during an oral presentation. The score earned by each group for this proposal is consistent in both of the classes, further reinforcing the idea that technical writing is a part of chemical engineering, not a separate subject. This paper will introduce the structure of the learning community linking the laboratory and technical writing courses and discuss the results seen in student assessments and evaluations since it was first introduced. This discussion will include suggestions for implementing similar learning communities in other engineering disciplines.

\section{Introduction}

The ability to communicate effectively is a very important part of a practicing engineer's job in every industry. One of the general requirements for accreditation of engineering programs by ABET is to demonstrate "an ability to apply written, oral, and graphical communication in both technical and non-technical environments; and an ability to identify and use appropriate technical literature;" as listed in student outcome $G$ in the ABET literature. ${ }^{1}$ In chemical engineering, as in many other disciplines, departments use laboratory courses to help develop the communication skills that are required to meet these goals. In addition, students are typically required to fulfill some sort of technical writing course requirement in order to graduate. In the Department of Chemical and Biological Engineering at Iowa State University, a new approach has been taken to teach the technical writing skills, as well as other communication skills, and apply these within 
the context of the undergraduate laboratory setting. A learning community has been created in order to link the technical writing course (English 314) with the first of two required laboratory courses (ChE 325), in hopes that the connection between good communication skills and good engineering practice will be better understood by students. The students and instructors receive benefits from this approach to teaching. The instructors are able to collaborate and ensure that consistent instruction is given, which is specific to typical chemical engineering practice. For the students, the consistent message received from both the engineering instructor and the English instructor helps to eliminate confusion about how to write technical papers, and it is specific to their field of study. The students receive the assistance of a peer mentor who is a more senior student in chemical engineering, who works closely with the instructors to provide additional help to the students. They also receive the benefit of a few joint assignments: a paper will be submitted in both the laboratory course and in the English course at the same time. This allows them to receive feedback from multiple people who are specifically evaluating different aspects of their writing: technical content and writing skills.

\section{Methods}

In early 2011 the Department of English was contacted by a faculty member from the Department of Chemical and Biological Engineering to discuss the possibility of teaching dedicated sections of English 314 (Technical Writing) with a focus on writing methods specific to the chemical engineering field. Because the Department of English had already begun teaching sections dedicated to different departments in the College of Business, and one for mechanical engineers, this was a concept that had support in the department and there was interest in pursuing it within both departments. In the summer of 2011 plans were made and the instructors (the authors of this paper) had several meetings to discuss the texts to be used, the schedule of assignments, and to gain an understanding of each other's' perspectives and what expectations would be laid out for the students.

The first offering of the linked courses was in Spring 2012 and included one section of 24 students in the English 314 class and two sections totaling 50 students in the ChE 325 class. Note that not all students in 325 were also co-enrolled in the technical writing class, because many of them had either already taken the writing course or they were unaware of the linked offering. During the Fall 2012 semester, the numbers of students in the technical writing and lab courses were 20 and 35, respectively. During each ensuing semester, the numbers increased in both courses, with Spring 2014 involving 44 and 63 students, respectively.

Because the Department of English wishes to fill all seats in every section of English 314, seats were opened to allow 24 students in the technical writing sections, but these seats were restricted to chemical engineering students. This allowed students who had already taken the lab course or those who planned to take the lab course while on study abroad to participate in the dedicated section of English 314. 
Implementation of the learning community required several changes in both courses. In the lab course, special lectures and "writing workshops" were eliminated from the course schedule. This opened up time for an additional experiment to be conducted during the semester. In the English course, two very specific changes were made. First, instead of teaching how to write a general technical report on an engineering or scientific process, the instructor taught specifically to the writing of a formal experimental report. Second, the teaching of generic project proposal was changed to specifically address the final design project in the laboratory course. This project requires students to design a possible new experiment for the laboratory course, and is presented as a proposal at the end of the semester. Additionally, a section was added for technical descriptions, and the section that addresses job application letters was altered to focus on only job opportunities in the chemical engineering field.

A peer mentor was enlisted to assist with the learning community. This is an upper-level chemical engineering student who has already completed the lab and technical writing courses, and who works with the instructors to schedule special help sessions to present information to the students in a timely manner. This person was also available for students who were not coenrolled in the classes, to help ensure consistency in report formats and to answer questions. This student is financially supported by the university's learning community program, and additionally by the Department of Chemical and Biological Engineering. The position is an hourly paid position, and the peer mentor holds weekly office hours as well as help sessions specifically addressing the issues that the students are facing in the classes at a given time during the semester. This allows the students to ask questions more specifically and freely than they may be willing to in class, and also allows the instructors to get feedback from regarding any sources of confusion or contradicting information that the students may have received.

Initial challenges were faced in implementing the course. These included advertisement of the linked courses and resistance of the students to change their schedules to accommodate the linked sections. Over the past two years, these challenges have largely been overcome. The students have heard from older students who have participated in the learning community and have seen the benefits of participation. A change in the advising system in chemical engineering has allowed for consistent communication about the learning community and encouragement from advisers to take the courses together. Some discussion has occurred in the chemical engineering curriculum committee to make the learning community into a required series; however, this has not been implemented because of the number of students who participate in summer classes or study abroad and complete their lab courses in these settings, which would result in a large number of students needing exemptions from the requirement and may complicate the review of degree audits during ABET accreditation visits.

\section{Results}

One of the first major changes that occurred when the learning community (LTM) was offered was that the structure of the laboratory course changed. Over the years, several adjustments had 
been made to the laboratory course in order to accommodate the teaching of technical communication skills. This had included the removal of one experiment from the schedule and replacement of that experiment with various lectures and writing workshops. When the learning community was implemented, this experiment was added back into the schedule and the writing components were removed from the class schedule, since the topics covered are now covered in the technical writing course.

The first semester that the learning community was offered, the lab course instructor and graders noted a significant improvement in the writing abilities of the students who participated in the learning community compared to those who did not, and compared to those students in previous semesters. After the second semester, the same differences were noted, and the authors began to track scores of students who had participated in the learning community and those who had not. The data presented in Figures 1 to 6 below illustrate the differences that were seen. Note that the graders were not all constant in the lab courses; this is why data are illustrated specifically by semester. Variability is inherent in the fact that at least three to four different teaching assistants were used each semester to help assess student work, thus there was a need to evaluate each semester independently. In addition, to determine whether or not the differences in the data are significant, pooled t-tests were performed on the reported scores (the mean value for each group of students), with the hypothesis being $\mu_{1}=\mu_{2}$. P-values of less than 0.05 allow for rejection of that hypothesis, indicating a statistical significance between the two means exists. P-values are given above the scores shown in Figures 1 to 6 . It is important to note that these figures represent only one method of analysis for the performance of the two groups of students. Laboratory reports are graded with the following criteria in mind: depth of understanding, accuracy of calculations and application of theory, presentation of results, discussion of major concepts, and comparison of results to theory and other data. Scores are affected by all of these factors. However, evaluating lab report scores is a reasonable starting point when trying to determine whether the learning community has been a benefit to the students and their ability to communicate effectively. 


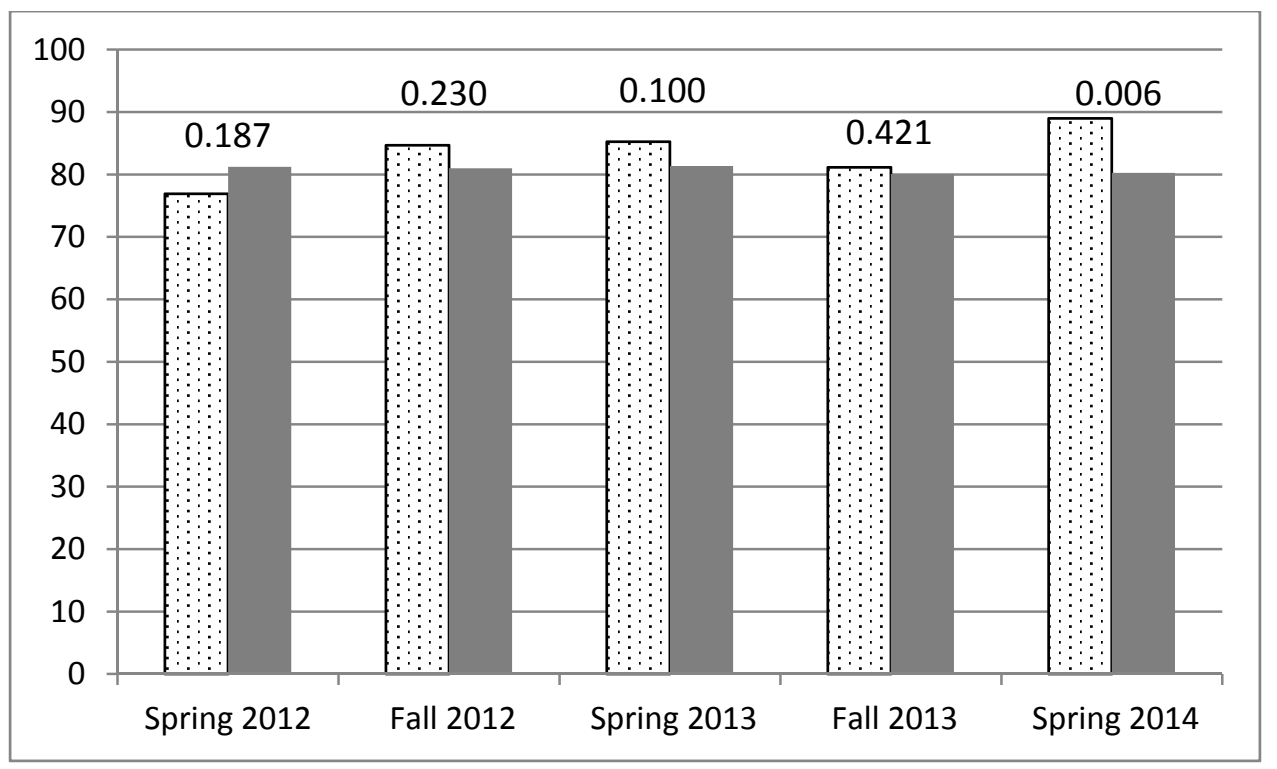

Figure 1: Scores for Report \#1 for students in the ChE 325 laboratory course over five semesters. The dotted bars indicate students in the learning community, while the solid indicate students not in the learning community. This report was based on a scale of 0-100 points. Scores for those in the learning community did not differ much from those who were not in the learning community at this point in the semester, with the average difference between the groups of students being less than $2 \%$.

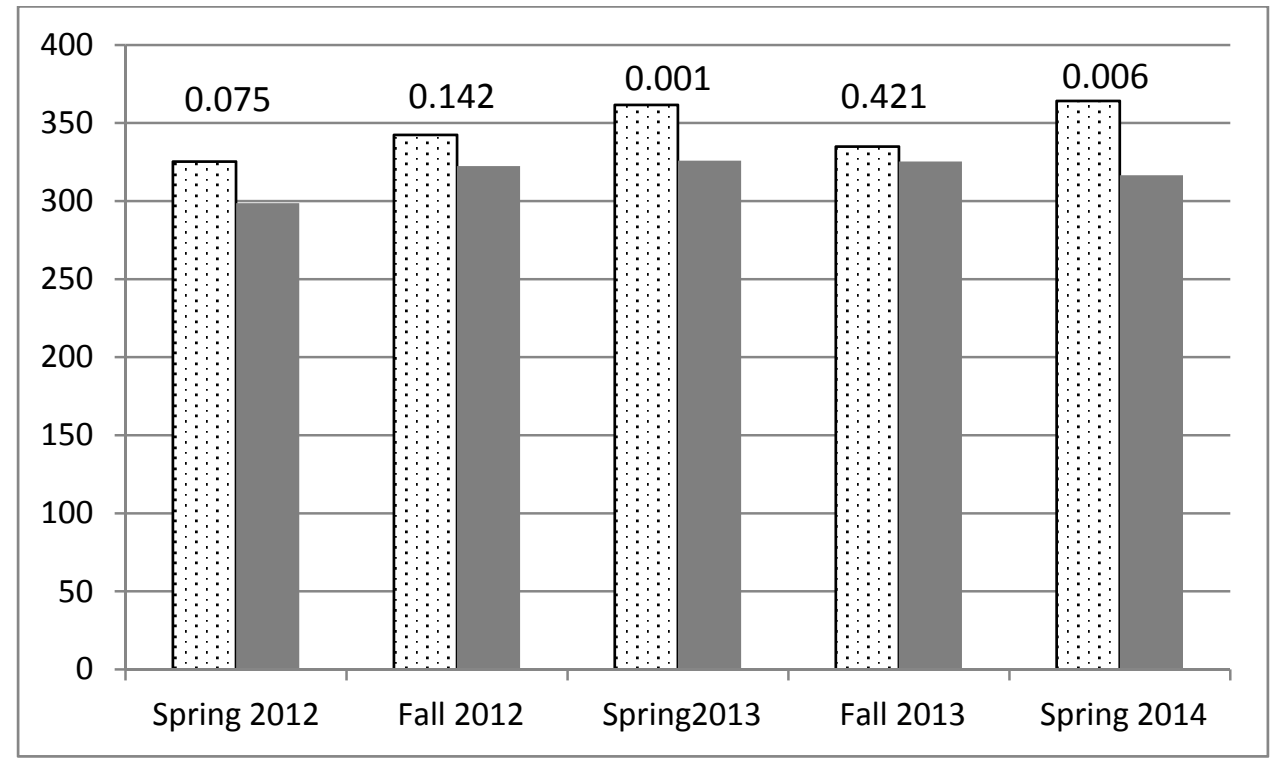

Figure 2: Scores for Report \#2 for students in the ChE 325 laboratory course over five semesters. The dotted bars indicate students in the learning community, while the solid indicate students not in the learning community. This report was based on a scale of 0-400 points. In each semester, the average scores for students in the learning community were higher than for those who were not. The average difference between these scores over the five semesters was nearly $8 \%$. 


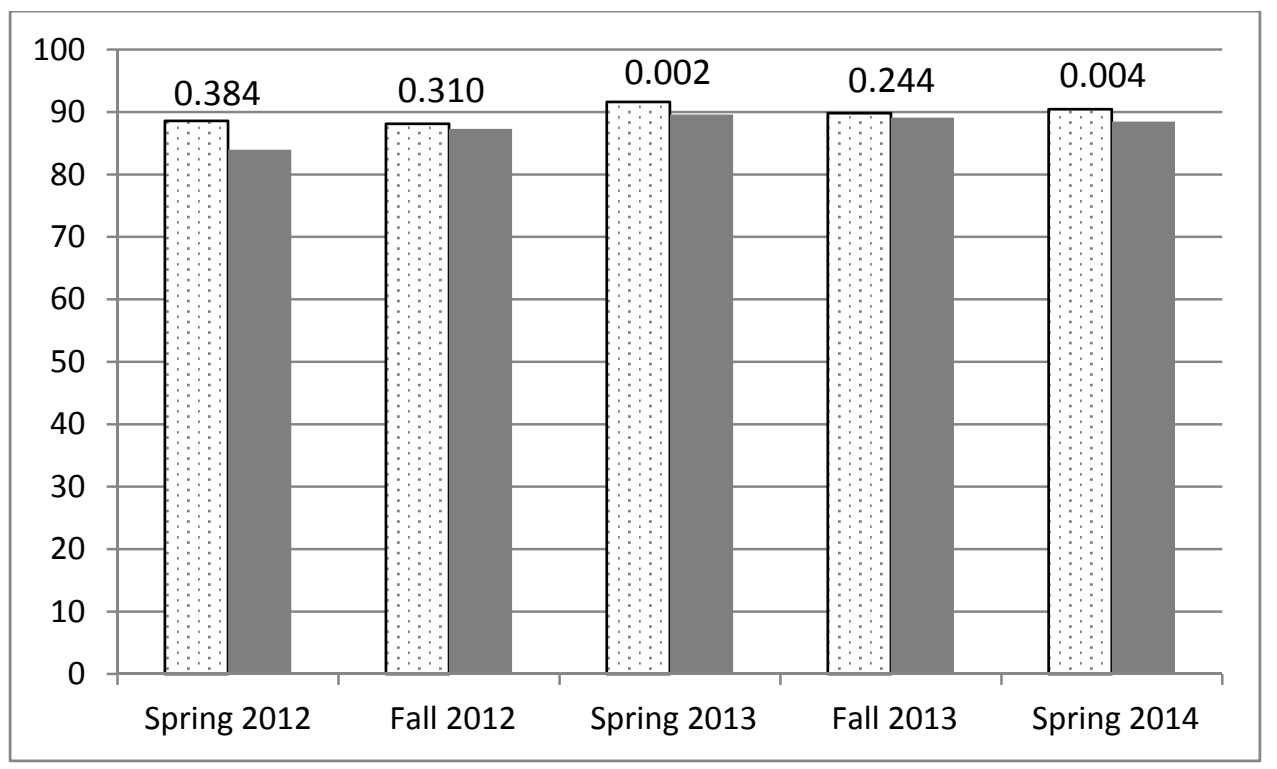

Figure 3: Scores for Report \#3 for students in the ChE 325 laboratory course over five semesters. The dotted bars indicate students in the learning community, while the solid indicate students not in the learning community. This report was based on a scale of 0-100 points. In each semester, the average scores for students in the learning community were not significantly different from those who were not; however, this is an oral presentation which is given as a group of two, with both partners receiving the same score, and therefore the separation between students who are or are not in the learning community is not clear.

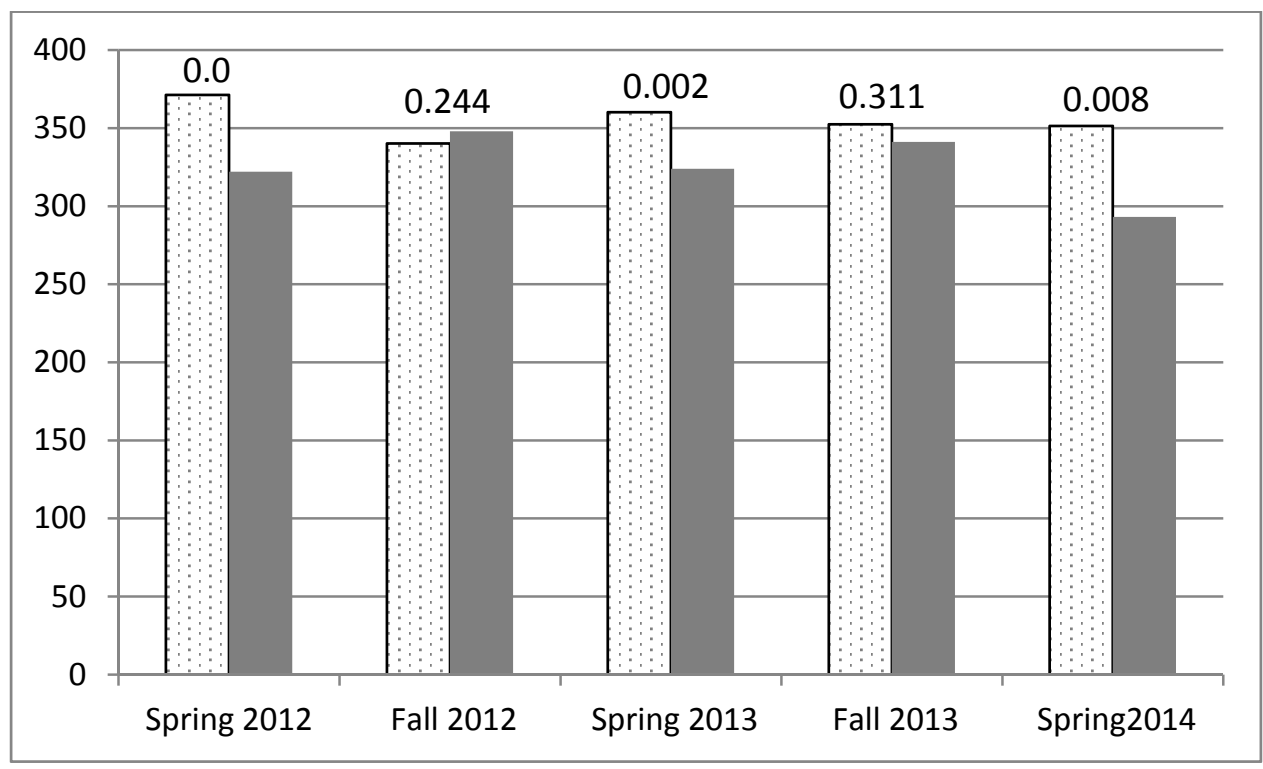

Figure 4: Scores for Report \#4 for students in the ChE 325 laboratory course over five semesters. The dotted bars indicate students in the learning community, while the solid indicate students not in the learning community. This report was based on a scale of 0-400 points. In four semesters, the average scores for students in the learning community were higher than for those who were 
not; the one semester in which the non-learning community students had an average higher score did not have a significant difference in scores. Even including that semester, the average difference between these scores over the five semesters was just over $8 \%$.

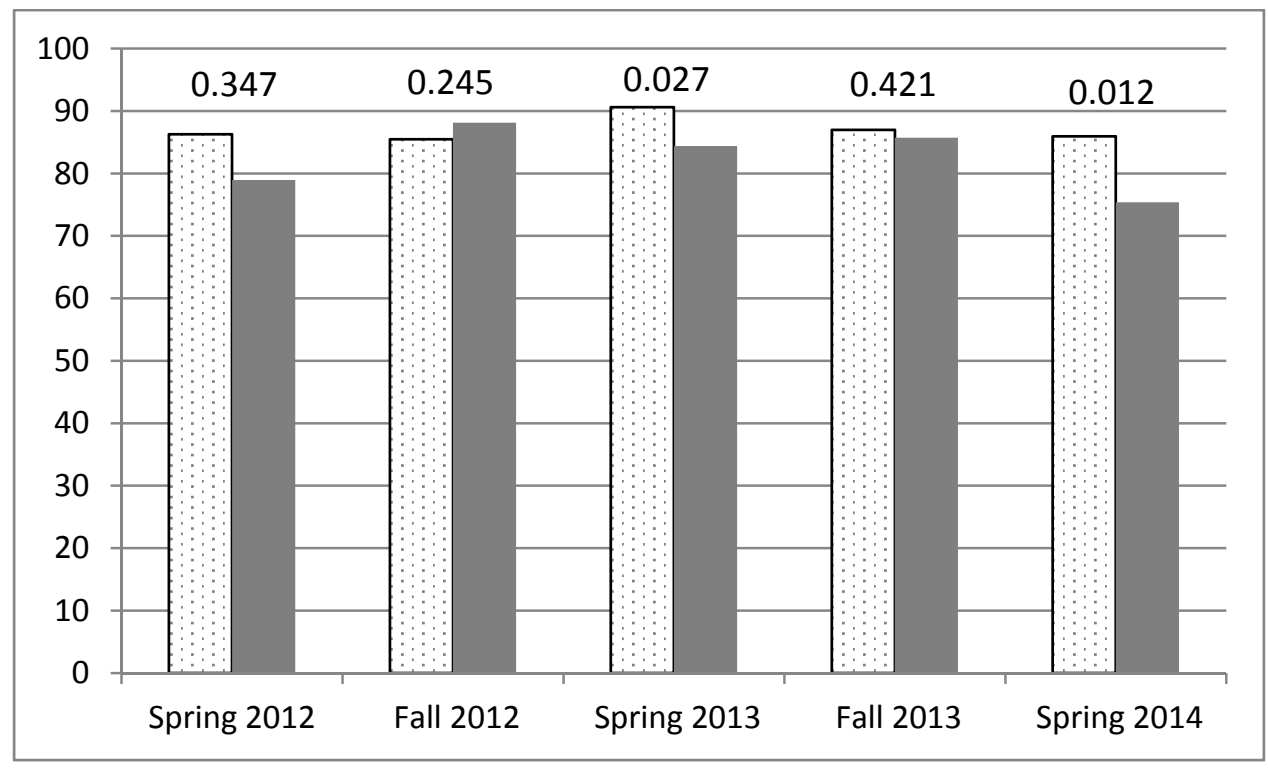

Figure 5: Scores for Report \#5 for students in the ChE 325 laboratory course over five semesters. The dotted bars indicate students in the learning community, while the solid indicate students not in the learning community. This report was based on a scale of 0-100 points. In each semester, the average scores for students in the learning community were higher than for those who were not. The average difference between these scores over the five semesters was over $5 \%$.

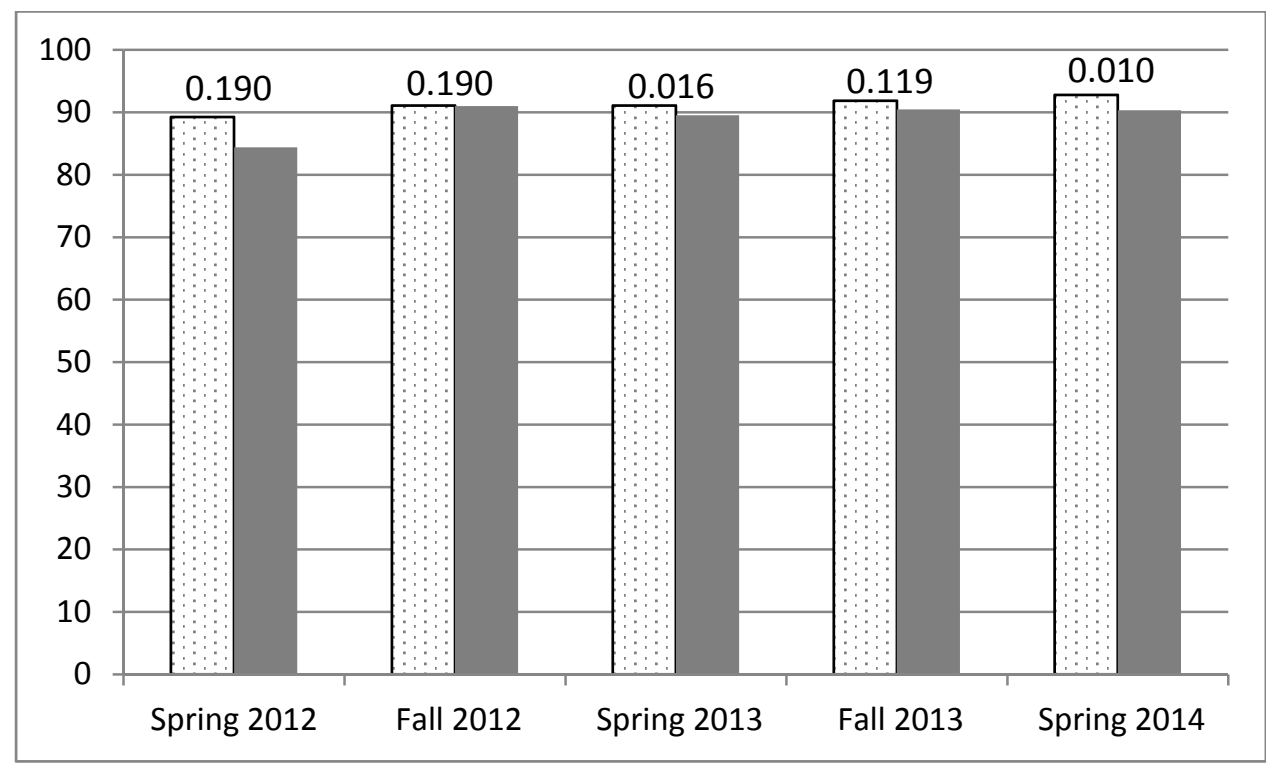

Figure 6: Scores for the Final Oral Report for students in the ChE 325 laboratory course over five semesters. The dotted bars indicate students in the learning community, while the solid 
indicate students not in the learning community. This report was based on a scale of 0-100 points. In each semester, the average scores for students in the learning community were not significantly different from those who were not; however, this is an oral presentation which is given as a group of two, with both partners receiving the same score, and therefore the separation between students who are or are not in the learning community is not clear. The average difference between groups of students is only $2 \%$.

\section{Discussion}

Figures 1-6 show that there is an average difference of up to $+16 \%$ in scores for the same assignments between the students who participated in the learning community and those who did not. Even more interesting to note, the average difference appears to increase over the course of the semester. Note that for the first assignment (Report \#1), which is assigned within the first three weeks of the semester, the difference in scores is negligible between the different groups, with some semesters showing that students in the learning community having an average score lower than those who are not in the learning community. The average difference in scores for Report \#1 was 2.87\%. As the semester progresses, the average difference in scores increases. For Report \#2, the average difference in scores is 7.97\%, for Report \#4 it is $8.15 \%$, and for Report \#5 it is $5.20 \%$. Report \#3 and the Final Oral Report are neglected because these are done as partners, and therefore are not necessarily representative of the separate groups. It is worth noting that the difference in scores for these two reports are $2.27 \%$ and $2.28 \%$, respectively. The fact that most groups have at least one person in the learning community leads the authors to believe that the non-LTM students are learning some of the communication skills taught in the linked technical writing class from their peers.

It is noted by the authors that not every semester shows a statistical significance between the average scores on the reports. As mentioned earlier, the scores are only one method of assessing the performance of the students. In addition to the average scores, some qualitative results can be reported. At the end of the semester, students have been noting the benefits of participating in the learning community on their course evaluations in both classes. They find that the link between the courses is useful because the English class focuses on topics essential to their major. They also report that they appreciate receiving feedback on both the technical and writing aspects of their reports from people with differing expertise, and they appreciate the advantage of having consistent instruction on report writing. In addition, they report that the investigation and response to problems in job searching within their chosen profession is helpful.

Implementation of linked learning at another institution would begin with conversations between the department chairperson of the "home" course (in this case, Chemical and Biological Engineering) and the chair of the department housing the linked course (in this case, the English department); faculty who are interested in teaching such linked courses might also be included in email discussions and the initial meeting. In such a linkage, the department leaders and course instructors must understand and agree upon mutual course objectives and work together to create 
two or more linked assignments that fulfill many of those objectives. Selecting a single textbook for use in both courses serves to unify the subject matter and strengthen the link. In the case of this link between chemical engineering and technical writing, the instructors chose a textbook on technical writing, authored by an engineering professional.

It is to be expected that the first semester will reveal issues in need of resolution, and the faculty involved with the course development will communicate through email and meetings to find the best ways to reconstruct the course content and approaches. Continuing communication between the course instructors is also essential for improving the quality of the link.

\section{Conclusions}

The implementation of a learning community to link the undergraduate laboratory course in chemical engineering with a technical writing course has shown benefits to the students and instructors. The students have access to a peer mentor, have joint assignments between the classes, and receive consistent instruction with regard to writing engineering reports. In each semester, the difference in report scores between those students in the learning community and those who are not is notable, and the difference in scores tends to increase as the semester progresses. Student response to the link between the courses has been overwhelmingly positive. The cooperation between the Departments of English and Chemical and Biological Engineering has resulted in improved communication skills for graduating chemical engineers, and similar learning communities could be used in other disciplines to help students better understand the importance of good communication skills and to better equip them for their future careers as engineers.

\section{Bibliography}

1. Criteria for Accrediting Engineering Technology Programs, The Accreditation Board for Engineering and Technology, http://www.abet.org/etac-criteria-2014-2015/, accessed July 26, 2014. 